Bull. Fac . Agric., Cairo Univ., 70: 307-316 (2019).

\title{
FARMERS' PREFERENCES OF THE INSTITUTIONAL REFORM SCENARIOS OF PROVIDING AGRICULTURAL EXTENSION SERVICES IN SOHAG, KAFR EL SHIEKH, AND SHARQIEA GOVERNORATES IN EGYPT
}

(Received:24.12.2019)

\author{
By \\ M.H. Nawar, E.M.El shafie and F.W. Segfrou \\ Rural Sociology and Agriculture Extension Department, Faculty of Agriculture, \\ Cairo University, Giza, Egypt
}

\begin{abstract}
The current Agricultural Extension (AE) system in Egypt is facing several challenges that hinder effective reaching to small landholders in the Delta and the Nile Valley of Egypt. Among these challenges are the ever-decreasing numbers of extension agents and the shrinking budgets. Along with the other contextual changes, this system needs drastic changes and rearrangements to face these challenges. This study investigated farmers' preference of three suggested scenarios for reforming the AE system. The study was conducted in three Governorates, namely: Sohag, Kafr El-Sheikh, and Sharqeia. One District was randomly selected in each Governorate, namely: El-Maragha, Kafr ElSheikh and Monshaat Omar, respectively. One village was randomly selected each of the selected Districts, namely: El-Shorania, Kafr Matboul and Monshaat Omar, respectively. The data were collected by applying a questionnaire in personal interviews with a random sample of 316 farmers, representing about $10 \%$ of the total population of farmers in the three selected villages. Frequencies, percentages, standard deviations and Chi-Square were utilized for data presentation and analysis. The results revealed that strengthening the current public agricultural extension organization was the scenario preferred by the majority (67.4\%) of the respondents. Public-Private Partnership through partnership between the public governmental and private sectors was the second preference for the respondents $(28.5 \%)$. Privatization of the agricultural extension organization was the least preferred by the respondents, as reported by only $3 \%$.
\end{abstract}

Key words: Agricultural Extension System, Institutional Reform, Egypt

\section{INTRODUCTION}

Organizations in society always need to adapt to changes that take place in the contexts and systems they belong to. Many researchers admit the fact that organizations do not adapt easily to changes in the contexts. Further, organizations that change do so in ways that are not always successful or effective. They must continually balance the forces of stability and the push for change across time (Cott, 1997). Organizations, throughout are shaped and reshaped by the forces of stability on one side and the need for change on the other (Chaudhary, 2018). The strength and utility of organizations come from their stability, which helps them become reliable in undertaking their activities and to be accountable for the services they offer to beneficiaries.

Social services' organizations address, in general, a wide range of low-income families and small households' needs, especially in rural areas. Such kind of agencies is, usually, part of larger systems that involve government provision of services and government funding for private institutions (Fink, et al., 2001).

However, when different aspects of organizational change take place, this might result in creating a resistance milieu towards these changes. Confusing understanding of the changes can drive the organization members to retreat the desires and the motivations to accept the new organization structure (Moore et al., 2012). Change processes are driven by several strategic considerations including the need for more integrated approaches of work and the need to improve the performance of activities. These considerations typically result in structured change programs based on the assumption that change management consists of a limited set of interventions (Pieterse, 
Marjolein et al., 2012).

This is what provoked the writers to focus light on one of the important organizations in developing agriculture in developing countries like Egypt. The Public Agricultural Extension Organization (PAEO) has gone through several drastic changes in the last three decades worldwide and where Egypt is not an exception.

Agricultural extension is in transition influenced by trends toward reduced government intervention in the economy, growth of the private sector and civil society, and globalization from one side and the speedy process of technological changes from the other side. These changes and a range of other pressures are forcing a reexamination of public extension services that are also shaped by a perceived poor performance of past investments in extension. Yet, due to the accumulated negative impacts of the weak performance of the agricultural extension sector, Egypt has adopted a number of development strategies to overcome the deterioration. These strategies include reform of the organizational structure in addition to the learned lessons that were adopted by different countries (Abdelghany and Diab, 2013). Furthermore, Abd El-Wahed and Deraz (2014) stated that the importance of the role of extension agencies as social change organization lies in carrying out several tasks related to the rural people livelihoods and their agricultural work.

\subsection{Problem Statement}

In spite of the vital role of the agricultural extension sector in achieving agricultural development within the framework of the Egyptian agricultural strategic plan 2030, Agricultural extension Organizations (AEO) suffer from stalemate that requires urgent measures to overcome this hurdle. It has started suffering from the chronic problem of reduction of the allocated budget since the launch of the structural adjustment program, in the late eighties. In addition, the aging of $\mathrm{AE}$ workers in PAEO, due to the frozen process of replacement of the retired agents, resulted in great difficulty in the implementation of Agricultural Extension (AE) activities. This situation affected more severely the uncovered agricultural remote areas with the AE services.

According to the Central Administration of Agricultural Extension and Environment (CAAEE), the number of agricultural extension workers in 2018 was 2503 serving the entire population of farmers distributed throughout the governorates of Egypt. This few number of extension workers cannot cover all villages and remote rural areas with the needed extension services.

The significance of the problem is based on the need to answer the question related to the opinions of AE services' beneficiaries regarding their preferences related to the restructuring of the AEO.

\subsection{Objectives of the study}

The objectives of this study include; a) to investigate the preferences of the different categories of farmers (small, medium and large scale) as end-users concerning the proposed new structural reforms of the agricultural extension system. It examines the tendency of preferences among the three categories of farmers towards three different institutional reform scenarios of the agricultural extension system, and b) to identify the relationship between the preferences of the end-users and some of their characteristics.

\section{MATERIALS}

\subsection{The current situation of the governmental AE services organization}

According to the CAAEE, the organizational structure of the AE services at the central level is represented by the CAAEE. At the Regional level, it consists of nine extension areas (North Delta, West Delta, North and Central Delta, East Delta, South and Central Delta, Northern Upper Egypt, Middle Egypt, Upper Egypt, North Coast). This organization considers the Agro-Ecological Zones (AEZs) where each zone represents a bundle of governorates and research centers.

At the governorate level, there is an agricultural extension department as part of the structure of the Agriculture Directorate (AD) in each governorate.

At the District level, there are 198 extension centers in some villages directly affiliated to the concerned ADs. They have been established to maximize the performance and encourage positive participation in the rural development programs through integration and coordination between the extension agents and all other local actors.

In spite of the previous organizational structure of the extension service that covers all the cultivated AEZs in Egypt, real beneficiaries (farmers) did not receive good services due to the following; a) Lack of strong and effective relationships between agricultural extension 
organizations and research institutes, b) Absence of effective communication between the farmers` organizations and the upper-level governmental organizations and c) Right now there are no extension workers exist at the village level due to the retirement of most of them.

\subsection{The need to reform the agricultural extension organization}

Kirkpatrick, (2014) stated that the most common forms of extension policies in most developing countries develop policies issued by the upper levels of the state administration without the consultation of the various stakeholders and beneficiaries. As reported by Abdelghany and Diab (2013) the environment of agricultural extension is changing. Agricultural extension is in transition influenced by trends toward reduced government intervention in the economy, growth of the private sector and civil society, and globalization. These changes and a range of other pressures are forcing for a reexamination of public extension services. The public services monopoly model for extension proved irresponsive in the more competitive, market-oriented climate of today's agriculture.

Decentralization, privatization, cost-sharing, cost recovery, and participation by stakeholders within a pluralistic financing and delivery system are some of the major reforms being pursued in extension's current transition.

Nagel (1997) reported that this has led to redefining the role of public $\mathrm{AE}$ services and rethinking of extension approaches other than the top-down approach. Though policy makers became aware of the global challenges that affect the delivery of public AE services, they could not predict the potential drawbacks of the new policies on the performance of the existing $\mathrm{AE}$ services organizational structure from the social perspective.

Over the past four decades, several interventions from private sector and other external aid agencies offered alternatives to the public $\mathrm{AE}$ systems that were trying not only to assess the performance of PAEO, but also to address related problems such as lack of public financial resources and lack of qualified extension personnel in agricultural coops. This led the main stakeholders, including governmental extension authorities, research institutions, the Civil Society Organizations (CSOs) and the rural community leaders, to critically review and rethink about the beneficiaries' demands and needs for reforming the organizational structure of the AE system to enhance its performance.

Aligned with this direction, the European Neighborhood Partnership Agriculture and Rural Development (ENPARD) conducted in 2016 a series of workshops to investigate related issues. The participants included panels of experts representing the main stakeholders, i.e. agricultural extension and rural development national agencies, international agencies, agricultural coops, agricultural research institutes, faculties of agriculture staff members, civil society associations, farmers` syndicate, and agricultural private sector

(Abd El-Hakiem,2016).

During these workshops the whole situation of AE system problems, challenges and possible interventions was assessed. As a final conclusion three different scenarios were suggested.

\subsection{Alternative structural reforms scenarios for the $\mathrm{AE}$ system for providing $\mathrm{AE}$ Services in the Egyptian context \\ 2.3.1. The first scenario: Strengthening the current PAEO}

Swanson and Raialah (2010) suggested that the establishment of a new organizational and administrative structure for a national $\mathrm{AE}$ system which requires recruiting of new qualified personnel and encouraging farmers to establish their CSOs to assess the priorities of the AE services including the offered programs and expenditures. As indicated by Nagel (1997) the fact that the ministerial hierarchy followed the country's territorial subdivision allowed for a systematic expansion of the $\mathrm{AE}$ system "down" to the village level. Usually, the small scale farmers used to get the advice from the $\mathrm{AE}$ personnel. On the other side, the large scale growers and agro investors get the technical recommendations from other sources such as the private sector. The ministry-based AE system has been incapable to reach the majority of potential clientele due to economic and technical restrictions. According to DTI (2012) the financial limitations were one of the reasons of reducing the numbers of $\mathrm{AE}$ personnel in African continent. The few numbers of personnel, remained in the cooperatives have not the capacity to satisfy the beneficiaries' needs and cope with the new planned strategies for expanding the cultivable land areas and increasing the national agricultural production.

Yet, the low quality of the AE services provided by the grass root level of $\mathrm{AE}$ workers 
in Egypt could be attributed to their old age which made them less eager to update their knowledge, in addition to the lack of on-service training in the areas of modern agricultural applications.

In this context, ENPARD suggested the first scenario of reform of the current governmental organizational structure, in Egypt, in terms of administrative rearrangement and financial resources mobilization. Concerning the organizational structure, this scenario suggests bringing reform for the current extension administration body relying on a proposal for the establishment of a Supreme Agricultural Extension Council (SAEC) that includes multidisciplinary representatives from academic, research institutes, finance, cooperatives, farmers, private sector agricultural production companies and agricultural input supplies companies. This is in order to achieve better coordination between research and agricultural extension policies. Such council will mainstream (CAAEE) which is responsible for the implementation of agricultural extension activities jointly with the agricultural research services. The Ministry of Agriculture and Land Reclamation (MALR) will be responsible for issuing agricultural legislations and polices.

Thus, the new structure of CAAEE will include the following general departments; Extension Programs Planning, Training, Rural Women and Youth, Marketing, Environment and Monitoring and Evaluation (M\&E).

Regarding the suggested financial resources, a reasonable proportion of the governmental budget will be allocated for the AE organization. This proportion could be gradually decreased and replaced by contributions of other financial resources such as:

-Profits of agricultural cooperatives.

-Profits of the Agricultural Development and Credit Bank.

-Taxes on agricultural lands.

-Fees paid by farmers for some agricultural services.

2.3.2. The second scenario: Privatization of the agricultural extension organization

As reported by Saliu and Age, (2009) the developing countries are currently oriented towards privatizing all the sectors that offer free services for its beneficiaries. AEO is one of the most seen sectors in these countries that should be privatized. This is based on the assumptionthat the private $\mathrm{AE}$ has flexible organizational structure that will be positively reflected on the quality of the offered service. The private extension services, as a scenario, advocate the belief that it will improve the efficiency, encourage competition of the development agents and private sector participation in addition to the significant reduction of the public expenditures.

According to ENPARD the main objectives of the AEO, within this scenario, will be rural development, human resource development and increasing agricultural productivity and net returns of farmers in order to improve their quality of rural life and wellbeing. These objectives could be achieved through establishing Public Private Partnerships (PPPs) among different organizations and structures including MALR, NGOs, private companies and all other stakeholders. This partnership could be established based on contract farming among farmers organized in a group (under any title such as NGO or Producers' Association or Cooperative), and a private company for input supply, marketing, processing or exporting the agricultural products. Contracting process needs to be supervised by MALR for quality control, protecting farmers' rights and judgment in case of disputes. This suggested organizational structure could lead to developing an AEO that minimizes governmental authority and intervention and thus secures providing producers with their needed and demanded $\mathrm{AE}$ services.

The suggested organizational structure of the AEO, under this scenario will include the CAAEE functioning under the supervision of the Agricultural Research Center (ARC). The departments of CAAEE will take care of the management of the partnership with private sector and risk management, in addition to four departments for Southern, Eastern, Western and Northern Regions. Two other departments for the $M \& E$ and food safety will be functioning across all AEZs.

Concerning the financial resources for this scenario, a considerable Governmental financial contribution should be allocated during the initial phase, and then replaced gradually by financial proportions from:

-Profits of selling agricultural input supplies and products of veterinary companies.

-The surplus revenues of agricultural cooperatives.

-CSOs contributions at the local level.

- Contributions from farmers' syndicates. 
Fees paid by farmers for specific agricultural services.

By the end of the initial phase of this scenario, the public funds could be gradually minimized until the AEO becomes financially independent and autonomous.

\subsubsection{The third scenario: A Public Private}

\section{Partnership through partnership} between the public governmental and private sectors

Three basic missions of $\mathrm{AE}$ are suggested to be assigned by this scenario, namely: farmers' rehabilitation, providing technical extension and advisory services and playing the role of marketing mediator among farmers and other stakeholders.

The suggested organizational structure of this scenario is totally different from the previous two scenarios. Policy making functions are assigned to the MALR whereas the other executive missions are assigned to the private sector, specifically the agro vocational organizations and CSOs.

MALR will be responsible for developing and implementing strategic plans including the appropriate extension activities, in addition to, conducting technical and administrative training for preparing accredited AE workers. Those workers might be recruited by farmers' CSOs to assume the $\mathrm{AE}$ responsibilities.

The government's funding responsibility will be reduced to cover the ministry-related tasks only. The basic financial resources could be as follows:

-The fees of AE services will be determined according to farmers` categories and type of the service provided,

- Proportion of the cultivated land taxes paid by land owners,

- Proportion of the profits allocated by agricultural exporting companies,

-Proportion of the return of marketing contracts among the farmers' groups and private companies.

Several advantages are expected to result from each of the three suggested scenarios. The first scenario is expected to: a)maintain and improve the available extension infrastructure that cover all the Governorates (agricultural extension centers, extension offices and centers for supporting rural communication), b) maximize the advantages of the accumulated experiences of the current $\mathrm{AE}$ workers through specific mechanisms, c) upscale the performance of the current $\mathrm{AE}$ workers and enhance the M\&E of their activities, and d) activate and improve the linkages between the AEO and the ARC institutes. The second scenario will bring a more flat governmental $\mathrm{AE}$ structure than the current one and will improve coordination among all stakeholders specially the private sector while improving and sustaining M\&E for all the related actors. The third scenario is expected to bring more resilient $\mathrm{AE}$ organizational structure especially for the governmental component. It will help establishing partnerships between public and private sectors in addition to supporting producers' organizations and other CSOs.

\section{METHODOLOGY}

The study was conducted in three Governorates, namely: Sohag, Kafr El-Sheikh, and Sharqeia. One District was randomly selected in each Governorate, namely: ElMaragha, Kafr El-Sheikh and Monshaat Omar, respectively. One village was randomly selected in each of the selected Districts, namely: ElShorania, Kafr Matboul and Monshaat Omar, respectively. A questionnaire was designed, and pretested on 15 farmers, for data collection. Data were collected through personal interviews with a random sample of 316 (22 females, and 294 males) farmers, representing about $10 \%$ of the total population of farmers in the three selected villages, namely 116 farmers from El-Shorania Village, 113 farmers from Kafr Matboul Village, and 97 farmers from Monshaat Omar Village. Each interviewed farmer was asked about his/her tendency to prefer one of the three suggested scenarios.

Frequencies, percentages, average means, standard deviations and Chi-Square were used for data presentation and analysis

\section{RESULTS AND DISCUSSION}

In correspondence with the main objective of the study, an analysis of the data related to the respondents' preferences towards the three different suggested scenarios of reform of the Agricultural Extension system was undertaken separately and in relation with some independent variables related to the respondents. These scenarios include; strengthening of the current public sector of $\mathrm{AE}$ system as the first alternative, full privatization of the AE services as the second alternative, and partnership between the public and private sectors in providing the AE services; i.e. mixed scenario as the third alternative. The independent variables 
included the respondents' age, experience in the agricultural work, educational status, and the landholding size.

4.1. Respondents' preference towards the three suggested alternative scenarios of reform of the AE systems

Members of the sample were asked to express their preference from among the three above mentioned scenarios of reform of the Agricultural extension services system. Data shown in Table (1) and Fig. (1) found that the majority of the respondents $(67.4 \%)$ prefer the first reform scenario of enhancing the public $\mathrm{AE}$ system, while $(28.5 \%)$ preferred the mixed scenario but only about (4\%) selected the second scenario of privatization of the AE system.

Table(1): Distribution of respondents by their scenario preference.

\begin{tabular}{|c|c|c|}
\hline $\begin{array}{c}\text { Alternative recommended } \\
\text { Scenario }\end{array}$ & No. & \% \\
\hline 1- Strengthening the current PAEO & 214 & 67.4 \\
\hline $\begin{array}{c}\text { 2- Privatization of the agricultural } \\
\text { extension organization }\end{array}$ & 12 & 3 \\
\hline $\begin{array}{c}\text { 3- A Public Private Partnership } \\
\text { through partnership } \\
\text { between the public } \\
\text { governmental and private } \\
\text { sectors }\end{array}$ & 90 & 28.5 \\
\hline Total & 316 & 99.9 \\
\hline
\end{tabular}

Source: collected filed data

\subsection{The relationship between the respondents, preference and their characteristics}

\subsubsection{The respondents' Age}

Age refers to the number of years the respondent has (to the nearest year) during this study.

The range of age of the respondents was between (21-84 years old), with an average (50.79 years old) and a standard deviation (SD)
(13.66). Age was classified into 3 categories, young farmers (21-40 years), middle age farmers (41-60 years) and old age farmers (61years and above).

Distribution of the sample by age categories according to the best scenario they selected shows that the majority of the farmers in all categories selected the first scenario. However, the high age category has $(75.6 \%)$ of its farmers selected this scenario against $(69.5 \%)$ and $(62.8 \%)$ for the young and middle categories respectively. On the other side, the third scenario got the second choice for all age categories with the highest percentage for the middle age with about $(33.3 \%)$ against $(26.8 \%)$ and $(20.5 \%)$ for young and old farmers respectively. On the contrary very small proportion of the sample preferred the second scenario.

In addition, results from chi-square test show that there is a significant difference at level 0.05 between Age categories concerning their preferences of the suggested scenario of reform of the AE system.

The reason for having the elder farmers selecting the first scenario might be due to their trust in the governmental sector, represented by the agricultural coops that offered better $\mathrm{AE}$ services in the past, though currently, they suffer its deterioration. They imply that, in the past, the Ministry was keen to recruit sufficient numbers of extension agents in each agricultural coop at the village level to do their job which they look for a similar alternative in the future.

4.2.2. The respondents' experience in the agricultural work

Experience in farming was measured by the years that each respondent spent working in farming which, meanwhile, reflects partially the age of the respondent.

The range of respondents' years of experience was between 5 months to 75 years, with an average of 33.31 years and a Standard

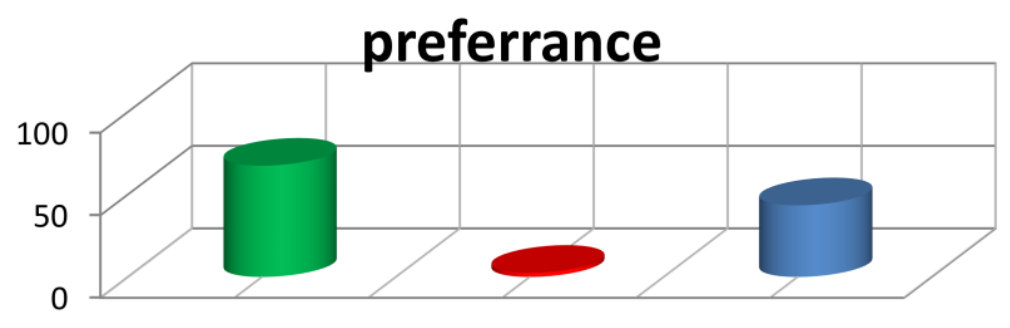

Fig.(1): Respondents' preferences of the AE reform scenarios. 
Table (2) : Farmers Age and their preference towards the suggested three AE systems.

\begin{tabular}{|c|c|c|c|c|c|c|c|c|}
\hline \multirow{3}{*}{$\begin{array}{c}\text { Age } \\
\text { Category }\end{array}$} & \multicolumn{6}{|c|}{ Suggested Reform Scenarios } & \multirow{2}{*}{\multicolumn{2}{|c|}{ Total }} \\
\hline & \multicolumn{2}{|c|}{ First } & \multicolumn{2}{|c|}{ Second } & \multicolumn{2}{|c|}{ Third } & & \\
\hline & No. & $\%$ & No. & $\%$ & No. & $\%$ & No. & $\%$ \\
\hline Young & 57 & 69.5 & 3 & 3.7 & 22 & 26.8 & 82 & 100 \\
\hline Middle & 98 & 62.8 & 6 & 3.8 & 52 & 33.3 & 156 & 100 \\
\hline Old & 59 & 75.6 & 3 & 3.8 & 16 & 20.5 & 78 & 100 \\
\hline Total & 214 & & 12 & & 90 & & 316 & \\
\hline
\end{tabular}

Deviation of 16.60 years. Years of experience in the agricultural work was classified into three categories, low experience farmers(1:10 years), medium experiences farmers(11-15 years) and highly experienced farmers(more than 15 years).

The no experience category was excluded from the analysis to emphasis on the impact of farmers' experience perse.

The sample distribution according to the farmers' years of experience in agricultural work shows that the highest rate of selection among the three scenarios of the AE system was for the first scenario for all categories. The majority of farmers with low experience $(68.75 \%)$ selected the first scenario against (65.54\%) and (64.18\%) for the medium and high experience categories respectively. On the other side, the third scenario got the second preference for all categories of years of experience with relatively near percentages $(30.24 \%), \quad(30.25 \%)$ and $(29.72 \%)$ for the low, high and medium experienced farmers respectively. On the contrary, none of the low experienced farmers preferred the second choice of privatization against (4.2\%) and (2.7\%) for high and medium categories respectively.

By testing the variables with $\mathrm{Chi}^{2}$, results showed that there is a highly significant difference at the 0.01 level among the farmers' categories with different period of experiences and their preferences of the three suggested reform scenarios.

The reason for choosing the first scenario may rely on the farmers' previous background of free of charge extension services offered to them by the governmental sector of agriculture in the past; i.e. since the sixties until late eighties. On the other hand, farmers support the third scenario with considerable percentage may be due to their awareness of the decline of the budget allocations to the $\mathrm{AE}$ sector under the current Economic Reform condition. While, they refused to support the privatization scenario probably because they experienced the higher costs of the agricultural inputs and supplies.

\subsubsection{The respondents' educational status:}

The educational status of respondent was measured by the number of years that he/she attended in formal education schools or alternative educational facilities

The range of respondents' formal years of education was between Zero and 16 years, with an average 5.89 years and Standard Deviation of 5.7 years. Distribution of the sample according to the years of formal education was classified into four categories, illiterate farmers ( 0 years), elementary educated framers (1-6years) medium educated farmers (between 7-12 years) and highly educated farmers (13-16 years) of formal

Table (3) : Farmers years of experience in the agricultural work and their preference towards the three suggested AE systems

\begin{tabular}{|l|c|c|c|c|c|c|c|c|}
\hline \multirow{2}{*}{$\begin{array}{c}\text { Exp. } \\
\text { years }\end{array}$} & \multicolumn{6}{|c|}{ Suggested Reform Scenarios } & \multicolumn{2}{c|}{ Total } \\
\cline { 2 - 9 } & No. & $\mathbf{\%}$ & No. & $\mathbf{\%}$ & No. & \% & No. & $\%$ \\
\hline Low & 11 & 68.75 & 0 & 0 & 5 & 31.24 & 16 & 100 \\
\hline Medium & 25 & 64.18 & 1 & 2.7 & 11 & 29.72 & 37 & 100 \\
\hline High & 156 & 65.54 & 10 & 4.2 & 72 & 30.25 & 238 & 100 \\
\hline Total & 192 & & 11 & & 88 & & 291 & \\
\hline
\end{tabular}

Note: There was a number of 25 of the sample had no previous experience in farming

$\chi^{2}=22.583 * *$ Source: collected field data 
education.

Breakdown of the distribution of the farmers' sample by both their years of formal education and the best scenario they selected shows that the majority of farmers in all categories selected the first scenario. However, about $68.75 \%$ of the illiterate category selected this scenario against $(67.69 \%),(63.41 \%)$ and $(57.77 \%)$ for the elementary, high and medium educated farmer categories respectively. On the other hand, the third scenario came as the second preference for all categories, as reported by $(36.6 \%)$ of the medium educated farmers against $(30.67 \%),(29.2 \%)$ and $(20.83 \%)$ of the elementary, high educated and illiterate farmers respectively. On the contrary, the second scenario of privatization came in the third preference for all categories with $(7.31 \%)$ for high educated farmer against (5.55\%), (2.5\%), and $(1.53 \%)$ for medium, illiterate and elementary educated farmers' categories respectively. the renewable policies of the government towards enhancing better performance of $\mathrm{AE}$ sector.

\subsubsection{Total land holding}

Total land holding of the respondent was measured by the sum of the owned, crop sharing and leased agricultural lands that he/she controls in the agricultural and farming activities according to the local agricultural coops.

The range of respondents' total area of land holding was between 4 and 2040 Kerats*, with the average of 64.96 Kerats and a Standard Deviation of 130.12 Kerats. Distribution of the sample according to the total land holding area was classified into three categories, small land holders with less than 24 Kerats, medium land holders' between 24 to 72 Kerat and large land holders with more than 72 Kerats of the agricultural land.

* Kerat is a unit used in the Egyptian context to measure the area of the agricultural land.

Table (4) : Farmers' education level and their preferences of the three suggested AE systems.

\begin{tabular}{|c|c|c|c|c|c|c|c|c|}
\hline \multirow{3}{*}{ Educational Status } & \multicolumn{8}{|c|}{ Suggested Reform Scenarios } \\
\hline & \multicolumn{2}{|c|}{ First } & \multicolumn{2}{|c|}{ Second } & \multicolumn{2}{|c|}{ Third } & \multicolumn{2}{|c|}{ Total } \\
\hline & No. & $\%$ & No. & $\%$ & No. & $\%$ & No. & $\%$ \\
\hline Illiterate & 92 & 76.66 & 3 & 2.5 & 25 & 20.83 & 120 & 100 \\
\hline Elementary & 44 & 67.69 & 1 & 1.53 & 20 & 30.76 & 65 & 100 \\
\hline Med. & 52 & 57.77 & 5 & 5.55 & 33 & 36.6 & 90 & 100 \\
\hline High & 26 & 63.41 & 3 & 7.31 & 12 & 29.2 & 41 & 100 \\
\hline Total & 214 & & 12 & & 90 & & 316 & \\
\hline
\end{tabular}

$\chi^{2}=20.3 * *$ Source: collected field data

By testing the variables with $\mathrm{Chi}^{2}$, results showed that there is a highly significant difference at the 0.01 level among the farmers' categories with different educational levels and their preferences of the three suggested scenarios.

The selection of the first scenario by the majority of the respondents could be attributed to their relatively low level of socio-economic conditions (about 37\% are illiterates and about $41 \%$ are small scale farmers), accustomed on the past on relying on the information and advice provided by the Governmental extension personnel working in Agricultural cooperatives.

The third scenario was supported by considerable proportions of the respondents (36.6\% and $29.2 \%$ for the medium and high educated categories respectively) that could be interpreted by their relatively better levels of education, considering that they are aware about
The sample distribution according to the farmers' land holding shows that the most preferred $\mathrm{AE}$ system is the first scenario for all categories. The majority of farmers who selected the first scenario are small scale farmers $(75.5 \%)$ against $(68.57 \%)$ and $(58.26 \%)$ for large, medium scale farmers respectively. On the other hand, the third scenario got the second preference for all categories of the land holding. For those farmers, the medium scale framers revealed $(36.56 \%)$ against $(28.57 \%)$ and $(21.3 \%)$ for the large scale and small scale farmers respectively.

On the opposite side the second scenario got the third preference with $(5.2 \%)$ against $(3 \%)$ and $(2.8 \%)$ for medium, small and large scale farmers.

By testing significance of the relationship between the variables with $\mathrm{Chi}^{2}$ the results showed that there are highly significant 
Table (5) : Farmers' total land holding and their preferences toward the three suggested AE system.

\begin{tabular}{|c|c|c|c|c|c|c|c|c|}
\hline \multirow{3}{*}{ Land Holding Cat. } & \multicolumn{8}{|c|}{ Suggested Reform Scenarios } \\
\hline & \multicolumn{2}{|c|}{ First } & \multicolumn{2}{|c|}{ Second } & \multicolumn{2}{|c|}{ Third } & \multicolumn{2}{|c|}{ Total } \\
\hline & No. & $\%$ & No. & $\%$ & No. & $\%$ & No. & $\%$ \\
\hline Small & 99 & 75.5 & 4 & 3 & 28 & 21.3 & 131 & 100 \\
\hline Med. & 67 & 58.26 & 6 & 5.2 & 42 & 36.52 & 115 & 100 \\
\hline Large & 48 & 68.57 & 2 & 2.8 & 20 & 28.57 & 70 & 100 \\
\hline Total & 214 & & 12 & & 90 & & 316 & \\
\hline
\end{tabular}

differences, at the 0.01 level, between farmers' land holding categories and their preferences towards the three suggested AE systems.

The selection of the first scenario by relatively high proportions of all land holding categories, especially the small land holders, could be interpreted by their tendency to avoid the possible high costs needed for affording private extension services provided through the second scenario. This tendency is supported or aggravated by their complaints and suffering from the high and ever-increasing costs of production requirements and inputs.

\section{Conclusion}

Based on the results of the study two main conclusions could be driven:

1)The majority of the respondents (67.4\%) prefer the first scenario of "Strengthening the current PAEO". The third PPP scenario through partnership between the public governmental and private sectors" came in the second rank of the preferences (28.5\%) while the second scenario of "privatization" was not accepted by the majority of respondents. The tendency to prefer the first scenario among the majority of respondents could be interpreted by their relatively old age (50 years old and more) which indicates two important points:

2)Their previous good experiences with the public AE system with its free services before the liberalization process,

3)Their reluctance to pay full fee for $\mathrm{AE}$ services.

4)The tendency of the respondents who prefer the third scenario "PPP between the public governmental and private sectors" could be a reflection of their perception about the critical current situation of the public $\mathrm{AE}$ system, in terms of the ever decreasing number of village $\mathrm{AE}$ workers and the shrinking of the governmental budgets allocated to the agricultural extension system. Therefore, they demonstrate their willingness to contribute to the costs of the $\mathrm{AE}$ services provided to them especially these related to the technical services such as water and soil analysis, LASER land leveling, diagnosing plant and animal diseases and any other advisory service.

5) Rejecting the second scenario "privatization" by $97 \%$ of the respondents could be attributed to the low economic status of the majority of farmers who mostly hold small land farms, the ever increasing prices of the agricultural inputs and the decreasing of governmental subsides provided to them.

\section{REFERENCES}

Abdelghany M.. and Diab A. M. (2013). Reforming Agricultural Extension in Egypt From The Viewpoint Of Central Level Extension Employees. Arab Univ.J. Agric. Sci.,Ain Shams Univ.,Cairo , 21 (2): 141-151.

Chaudhary M. (2018). https://www.cmccanada.ca/consult/articles/all-topics/fourchange-management-trends-to-watch-in-

2018. Retrieved from https://www.cmccanada.ca/consult/home (accecced 15 May 2019)

Cott D. D. (1997). Enhancing Organizational Performance. Washington, D.C.: NATIONAL ACADEMY PRESS.

DTI T. (2012). Integrated Strategy on the Development and Promotion Of CoOpratives, (2010-2022) Department trade and Industry (Dti) Republic of South Africa.

Fink B., Widom R., Beaulaurier R.., Contreras G., Dilley L. and Kissane R. J. (2001). 
Social Service Organizations. Manpower Demonstration Research Corporation.

Kirkpatrick C. (2014).Assessing the Impact of regulatory reform in developing countries, j. Wiley online library, 2014, P.34, 162168.

Moore C., Detert J.R., Trevino L.K., Baker V.L., and Mayer D.M. (2012). Why employees do bad Things: Moral disengagement and unethical organizational behavior. Personal Psychology , 65, 1-48. UK.

Nagel J.U. (1997). Improving agricultural extension. Arelerance manual- chapter 2Alternative approaches to organizing extension, Rome, Publisher, Food and Agriculture Organization.

Saliu O.J., and Age A.I. (2009).Privatization of Agricultural Extension services in Nigeria. Proposed Guidelines of implemenation. J. Sastainable

Development in Africa ,11, No2.

Swanson B. E. and Raialah R. (2010).

Strengtheing Agricultural Extension and

Advisory Systems procedures for

Assessing, Transforming and Evaluating

Extension . International Bank for

Reconstruction and Development/The World Bank.

عبد الحكيم ، تهانى (2016) .إستصلاح نظام الإرشاد

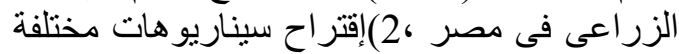

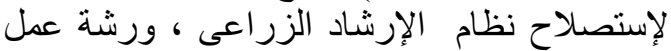
ENPARD،

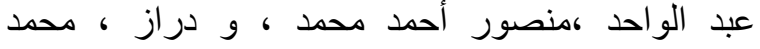

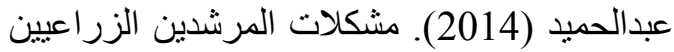
العاملين بالإرشاد الزر اعى بمحافظة البحيرة ، مجلة المبنة جامعة أسيوط ، المجلد (40) ، الاردئ الزئ العدد (4): 140.158

$$
\begin{aligned}
& \text { تفضيلات المزارعين لسيناريوهات الإصلاح المؤسسي لتوفير خدمات الارشاد الزراعي }
\end{aligned}
$$

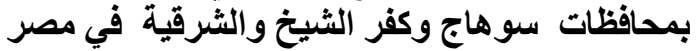

$$
\begin{aligned}
& \text { محمد حلمى نوار - عماد مختار الشافعى ـ فادى وجدى سيجفروا } \\
& \text { قسم الإرشاد الزر اعى و الإجتماع الريفى ـ كلية الزر اعة ـ جامعة القاهرة ـ الجيزة ـ مصر }
\end{aligned}
$$

يو اجه نظام الإرشاد الزراعي الحكومي الحالي في مصر العديد من التحديات التي تعوق الوصول التصول الفعال لخدمات

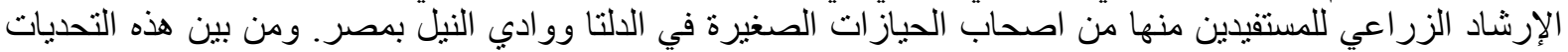

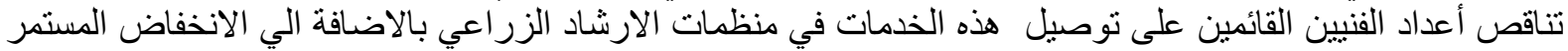

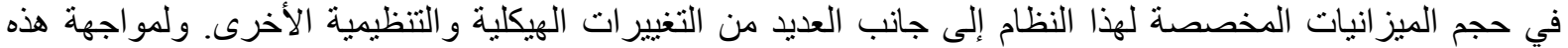

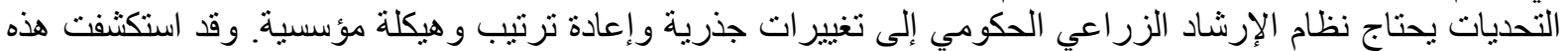

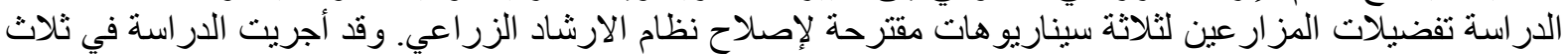

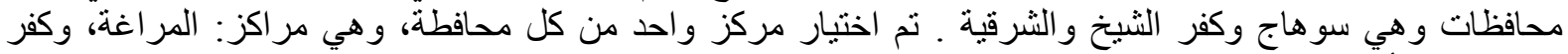

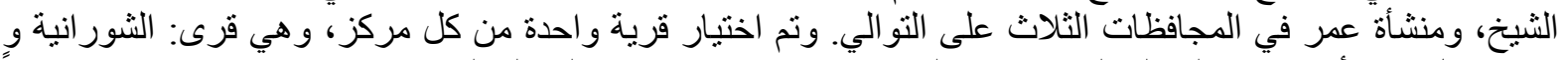

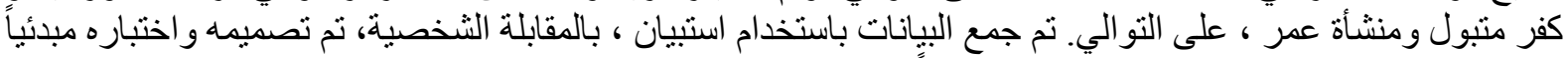

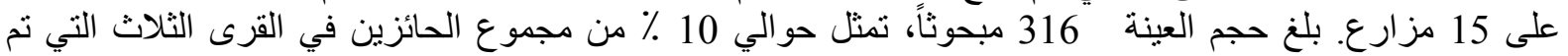

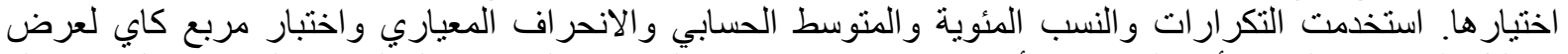
وتحليل البيانات. تتلخص أهم النتائج في أن تدعيم منظمة الإرشاد الزّراعي الزئ الحكومي الحالي هو السيناريو الذي الذي تفضله أغلبية المبحوثين(67.4\%). كانت الثراكة بين القطاعين العام والخاص هي التفضيل الثاني في الأهمبة للمبحوثين (بنسبة

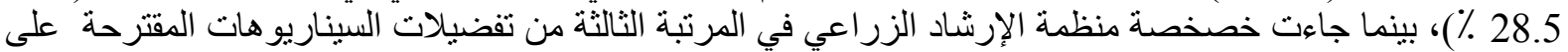

المبحوثين بنسبة 3 \% فقط.

المجلة العلمية لكلية الزراعة - جامعة القاهرة - العدد الرابع (أكتوبر 2019): 307-316. 